\section{Pleural infection}

John M Wrightson, clinical research fellow and respiratory specialist registrar, Oxford Pleural Unit, Churchill Hospital, Oxford and NIHR Oxford Biomedical Research Centre, University of Oxford; Nick A Maskell, senior lecturer and consultant in respiratory medicine, North Bristol Lung Centre, Southmead Hospital, Bristol University

Pleural infection affects more than 65,000 patients per year in the UK and USA with an accompanying mortality of up to $20 \% .^{1}$ The median length of hospital stay is $12-15$ days but $25 \%$ of these patients are inpatients for more than one month. ${ }^{2-5}$ The infection occurs most commonly in association with pneumonia. Up to $57 \%$ of patients with pneumonia develop a parapneumonic pleural effusion, ${ }^{6}$ varying in size from a very small effusion, not visible on the chest $\mathrm{x}$-ray, to a large effusion causing significant ventilatory compromise. Most of these effusions are reactive, non-infected 'simple effusions', but approximately $40 \%$ are infected ${ }^{7}$ : they are termed 'complicated effusions', and 'empyema' when pus cells are evident macroscopically.

\section{Clinical features}

Patients may either present with sepsis and symptoms of pneumonia, such as fever, cough, sputum production and dyspnoea, or have a more indolent history with constitutional symptoms such as weight loss and night sweats, with parietal pleural inflammation causing pleuritic chest pain. Physical examination commonly suggests a pleural effusion, although small effusions may be detected only by imaging. Patients with non-resolving pneumonia should be suspected of having pleural infection. In particular, ongoing fevers or non-improving white cell count or C-reactive protein (CRP) after three days of antibiotic therapy should lead to a reassessment for pleural fluid.

\section{Investigations}

Chest $x$-ray

Using routine chest $\mathrm{x}$-ray, parapneumonic effusions of over $200 \mathrm{ml}$ volume are usually detectable, associated with areas of consolidation. In addition, pleural infection often results in loculated effusions, occasionally with air-fluid levels.

\section{Pleural ultrasound}

Pleural ultrasound detects fluid in the pleural space with greater sensitivity than a chest $\mathrm{x}$-ray and, in addition, enables real-time localisation, quantification and characterisation of the fluid (Table 1, Fig 1). ${ }^{8,9}$ Selecting a site for pleural fluid drainage using bedside ultrasonography is safer than the traditional combination of chest $\mathrm{x}$-ray and clinical examination which carries a $10 \%$ risk of organ puncture. ${ }^{10}$ Thoracentesis-associated complications were reduced from $8 \%$ to $1 \%$ in one study when a safety programme, including physician-led chest ultrasonography, was introduced. ${ }^{11}$ Given such benefits, the recent British Thoracic Society

Table 1. Significance of pleural effusion sonographic findings.

$\begin{array}{ll}\text { Sonographic appearance } & \text { Significance } \\ \text { Echogenic (internal echoes } & \text { Exudative effusion } \\ \text { within pleural fluid) } & \text { Heavily echogenic fluid suggests blood or pus } \\ \text { Septated (visible lines } & \text { Exudative effusion } \\ \text { within pleural fluid) } & \text { Septations particularly suggest low pH, low glucose and high } \\ & \text { LDH } \\ & \text { Septation density may predict drainage success, but even } \\ \text { heavily septated effusions may drain well }\end{array}$

$\mathrm{LDH}=$ lactate dehydrogenase.

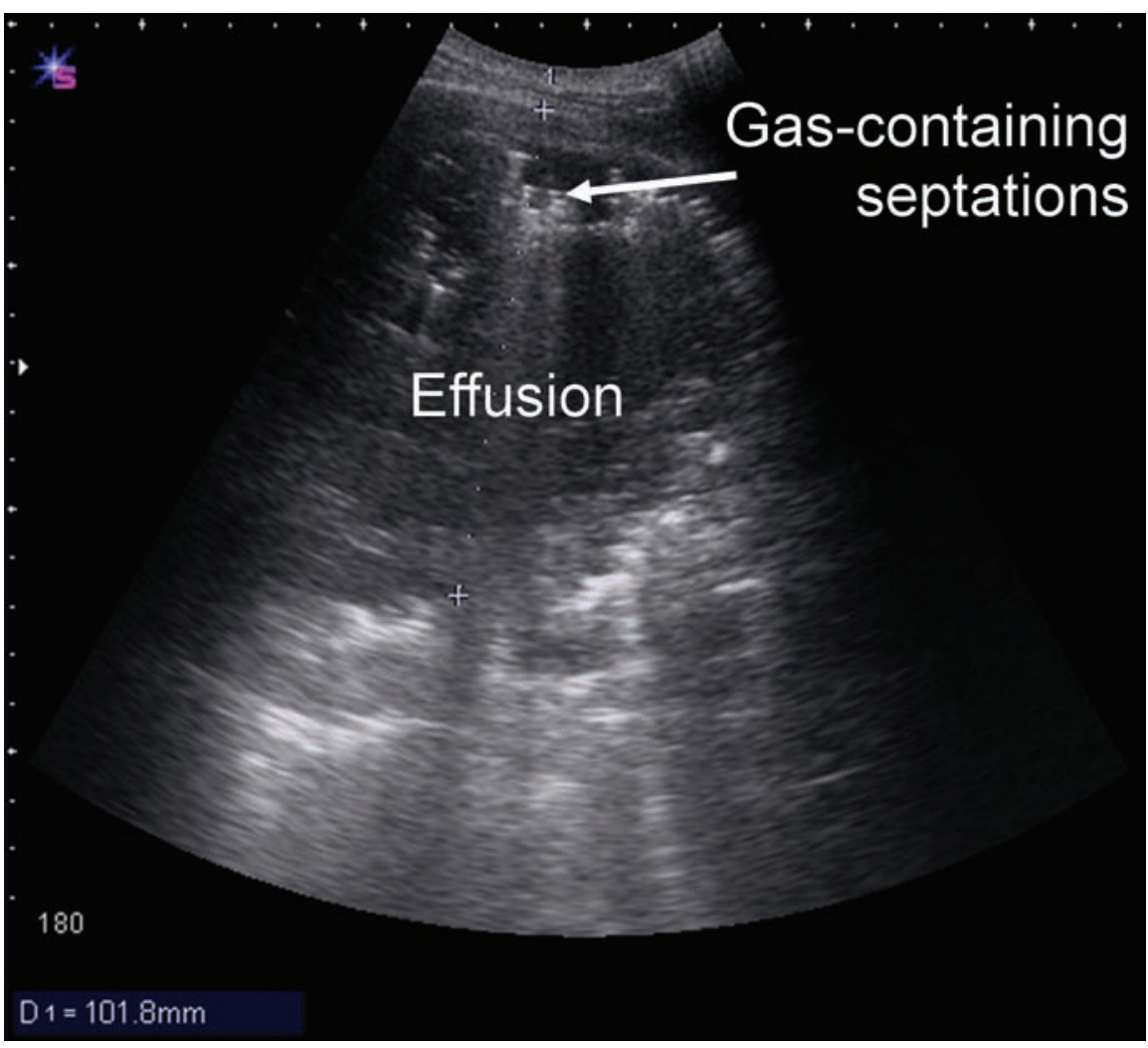

Fig 1. Ultrasound of a septated pleural effusion caused by gas-forming pleural infection. 
pleural disease guidelines ${ }^{12,13}$ and an NHS National Patient Safety Agency rapid response report ${ }^{14}$ now strongly recommend ultrasound prior to any procedure for pleural fluid. Furthermore, the Royal College of Radiologists has published ultrasound training guidelines for nonradiology clinicians. ${ }^{15}$

\section{Computed tomography}

Cross-sectional imaging of the chest with pleural-phase contrast enhancement is used for ambiguous chest x-ray or ultrasound findings. Pleural thickening, enhancement and increased attenuation of extrapleural subcostal fat suggest pleural infection. Computed tomography is particularly useful in differentiating a peripheral pulmonary abscess and pleural infection: the 'split pleura' sign found in pleural infection describes enhancement of parietal and visceral pleura around pleural fluid which is not found with a pulmonary abscess.

\section{Fluid sampling and analysis}

Imaging features may suggest pleural infection, but fluid sampling and analysis are essential to confirm infection. Parapneumonic effusions deeper than $1-2 \mathrm{~cm}$ should be sampled (provided it is safe to do so), even in the absence of specific imaging features suggestive of infection. Shallower effusions are likely to resolve with antibiotics, but clinical progress should be monitored. Table 2 details investigations to be undertaken for parapneumonic effusions.

Pleural fluid analysis provides effusion categorisation into:

- simple non-infected effusions

- complicated infected effusions

- empyema.

Biochemical proxies $(\mathrm{pH}$, glucose and lactate dehydrogenase $[\mathrm{LDH}])$ are used to define pleural infection (Table 3) - necessary because microbiological cultures are slow and frequently negative. Fluid $\mathrm{pH}$ is an important clinical predictor of pleural infection, ${ }^{18}$ although malignancy and other causes of inflammation may also cause $\mathrm{pH}$ values below 7.2. Glucose and
Table 2. Pleural fluid analysis.

\begin{tabular}{|c|c|c|}
\hline & Investigation & Comments \\
\hline \multirow[t]{2}{*}{ Bedside } & $\mathrm{pH}$ & $\begin{array}{l}\text { Use a blood gas syringe in a blood gas analysis } \\
\text { machine }\end{array}$ \\
\hline & & $\begin{array}{l}\text { Low pleural fluid } \mathrm{pH}(<7.2) \text { suggests need for } \\
\text { pleural drainage }\end{array}$ \\
\hline \multirow[t]{3}{*}{ Biochemistry } & TP, LDH & $\begin{array}{l}\text { Allows distinction between transudates and } \\
\text { exudates using Light's criteria }{ }^{16,17 *}\end{array}$ \\
\hline & & $\begin{array}{l}\text { Pleural infection is associated with exudative } \\
\text { pleural effusions which characteristically have } \\
\mathrm{LDH}>1,000 \mathrm{U} / \mathrm{I}\end{array}$ \\
\hline & Glucose & $\begin{array}{l}\text { Infection is associated with pleural fluid glucose } \\
<2.2 \mathrm{mmol} / \mathrm{l}\end{array}$ \\
\hline \multirow[t]{2}{*}{ Microbiology } & $\begin{array}{l}\text { Gram stain, culture } \\
\text { and sensitivity analyses }\end{array}$ & $\begin{array}{l}\text { Positive in } 40-60 \% \text { of patients with pleural } \\
\text { infection } \\
\text { Physicians should also have a low } \\
\text { threshold for mycobacterial culture }\end{array}$ \\
\hline & $\begin{array}{l}\text { Culture of pleural } \\
\text { fluid in 'blood culture } \\
\text { bottles' }\end{array}$ & $\begin{array}{l}\text { Bedside inoculation of fluid into aerobic and } \\
\text { anaerobic blood culture bottles increases } \\
\text { microbiological yield by ca } 20 \%\end{array}$ \\
\hline Cytology & Cytological examination & $\begin{array}{l}\text { Given that some cases of pleural malignancy } \\
\text { may mimic pleural infection (with low } \mathrm{pH} \text { and } \\
\text { glucose), cytological assessment is advocated }\end{array}$ \\
\hline \multicolumn{3}{|c|}{$\begin{array}{l}\text { *An exudate is defined as meeting one of the following criteria: } \\
\text { - pleural fluid TP: serum TP }>0.5 \\
\text { - pleural fluid LDH: serum LDH }>0.6 \\
\text { - pleural fluid LDH }>0.67 \text { of the serum LDH upper limit of normal }\end{array}$} \\
\hline \multicolumn{3}{|c|}{ LDH = lactate dehydrogenase; TP = total protein. } \\
\hline
\end{tabular}

LDH levels do not improve diagnostic reliability and primarily have utility only when accurate $\mathrm{pH}$ values are unavailable.

\section{Bacteriology}

It is essential for clinicians to acknowledge that the microbiology pattern of pleural infection varies between community and hospital-acquired infection. ${ }^{1}$ Gram-positive aerobic bacteria are the commonest cause of both community and healthcare-associated infection, Streptococcus pneumoniae (21\%) and the Streptococcus 'milleri'

\section{Key points}

Parapneumonic pleural effusions associated with pneumonia are infected in $40 \%$ of cases

Parapneumonic pleural effusions deeper than 1-2 cm must be sampled to confirm pleural infection; if present, immediate drainage and broad-spectrum antibiotic therapy are required

Pleural fluid acidity with a pH below 7.2 is used to define pleural infection requiring immediate drainage

Patients with poor response to medical therapy should be considered for thoracic surgical intervention at an early stage

Combination of intrapleural tissue plasminogen activator and deoxyribonuclease improves fluid drainage; further studies are required to define mortality and other benefits

KEY WORDS: chest tubes, empyema, parapneumonic effusion, pleural effusion, pneumonia 
Table 3. Characterisation of parapneumonic effusions.

Parapneumonic effusions

\begin{tabular}{|c|c|c|c|}
\hline Characteristic & Simple & Complicated & Empyema \\
\hline $\begin{array}{l}\text { Pneumonia-associated } \\
\text { effusions }\end{array}$ & ca $60 \%$ & \multicolumn{2}{|c|}{ ca $40 \%$} \\
\hline Appearance & $\begin{array}{l}\text { Clear or slightly } \\
\text { turbid }\end{array}$ & Usually cloudy & Pus \\
\hline $\mathrm{pH}$ & $\geqslant 7.20$ & $<7.20$ & Not usually measured \\
\hline Glucose & $\geqslant 2.2 \mathrm{mmol} / \mathrm{l}$ & $<2.2 \mathrm{mmol} / \mathrm{l}$ & Not usually measured \\
\hline LDH & $\leqslant 1,000 \quad U / I$ & $>1,000 \mathrm{U} / \mathrm{I}$ & Not usually measured \\
\hline $\begin{array}{l}\text { Microbiologically } \\
\text { positive? }\end{array}$ & No & ca $25 \%$ & ca $70 \%$ \\
\hline Usual treatment & $\begin{array}{l}\text { Antibiotic therapy } \\
\text { alone }\end{array}$ & \multicolumn{2}{|c|}{$\begin{array}{l}\text { Broad-spectrum antibiotics and chest tube } \\
\text { drainage }\end{array}$} \\
\hline
\end{tabular}

$\mathrm{LDH}=$ lactate dehydrogenase.

(constellatus-intermedius-anginosus) group $(24 \%)$ being the commonest in community-acquired infection and Staphylococcus aureus (35\%) being the commonest in hospital-acquired infection. Gram-negative organisms occur in about $9-23 \%$ of infections with anaerobic organisms in about $12-34 \%$. Polymicrobial infection is fairly common, particularly in the elderly and those with comorbidities. In healthcareassociated pleural infection, resistant pathogens such as methicillin-resistant Staphylococcus aureus and Gram-negative organisms such as Escherichia coli, Enterobacter spp and Pseudomonas spp are more common. Fungal pleural infection is rare, but important to consider in immunosuppressed patients. It has a mortality in excess of $70 \%$, with Candida spp the most commonly isolated fungus.

\section{Risk factors}

Pleural infection is more common in children and the elderly and its incidence is increasing across all age groups. ${ }^{2,3,19}$ Following the introduction of the 7valent pneumococcal conjugate vaccine, there is evidence that the non-vaccine serotype 1 is causing increasing cases of pleural infection and other invasive pneumococcal disease. Diabetes, the immunosuppressed state, alcohol misuse and intravenous (iv) drug abuse have been shown to be risk factors for pleural infection in adults. Aspiration and poor oral hygiene are more common in anaerobic pleural infection. A prospective study found the following predictive of development of complicated effusions in patients with pneumonia: ${ }^{7}$

- $\quad$ serum albumin below $30 \mathrm{~g} / \mathrm{l}$

- CRP above $100 \mathrm{mg} / \mathrm{l}$

- platelet count higher than $400 \times 10^{9} / 1$

- serum sodium below $130 \mathrm{mmol} / \mathrm{l}$

- iv drug use

- alcohol misuse.

\section{Other causes of infection}

Whilst pleural infection is normally associated with pneumonia, other causes should be considered when assessing patients. These include:

- oesophageal rupture and intraabdominal sources of infection (eg subphrenic abscess)

- traumatic pleural infection, secondary to penetrating or blunt chest trauma

- iatrogenic pleural infection, secondary to thoracic surgery or pleural procedures such as thoracentesis or chest tube insertion
- occasionally (ca 4\%), primary empyema in patients with no radiographic evidence of pneumonia or other cause

- Mycobacterium tuberculosis, a common cause of pleural effusion worldwide, but usually associated with a low mycobacterial load within the pleural cavity, normally developing as a type IV hypersensitivity reaction. Chest tube drainage is rarely required and the effusion usually responds to antituberculous therapy.

\section{Treatment}

\section{Antibiotic therapy}

Patients with pleural infection should be treated with empiric broad-spectrum antibiotic therapy until culture results are available. Antibiotic choice will be determined in accordance with local antibiotic policy and resistance patterns. However, as a guide, communityacquired pathogens are normally covered by a beta-lactam antibiotic in conjunction with a beta-lactamase inhibitor, such as amoxicillin and clavulanic acid or piperacillin-tazobactam. Metronidazole is frequently added to increase anaerobic coverage. Healthcare-associated pleural infection is often associated with resistant bacteria. A reasonable choice of antibiotic is a carbapenem combined with vancomycin.

Although not robustly tested in a randomised controlled trial (RCT) format, antibiotic treatment duration is usually given for 3-4 weeks. Initial therapy is with iv antibiotics for one week, guided by the clinical course.

\section{Pleural fluid drainage}

Pleural infection requires prompt tube drainage, but simple non-infected parapneumonic effusions do not usually require drainage. Recent evidence suggests that small-bore tubes $(<15 \mathrm{~F})$ have similar efficacy as large bore tubes in draining pus and are associated with less chest tube pain. ${ }^{20} \mathrm{~A}$ chest tube flush regimen, such as $20 \mathrm{ml} 0.9 \%$ sodium chloride solution every six hours, is often used for 
small-bore tubes together with suction using a dedicated thoracic suction unit.

\section{Adjunctive intrapleural medication}

The role of intrapleural fibrinolytics in improving the drainage of poorly resolving, heavily septated pleural infection has been investigated. Despite small studies suggesting that fibrinolytic streptokinase may improve fluid drainage when instilled into the pleural space, a large RCT (MIST-1) showed that intrapleural streptokinase did not improve clinical outcome. ${ }^{4}$ The MIST-2 RCT of intrapleural tissue plasminogen activator (tPA) and deoxyribonuclease (DNase), an enzyme which disrupts DNA, suggests that the combination of tPA and DNase increases the amount of pleural fluid drained. ${ }^{21}$ However, further studies are required to define the clinical treatment effect. A future trial should consider the combination of tPA and DNase in patients with ventilatory compromise and extensive comorbidities who are too high risk to undergo surgical intervention to evacuate the pleural space.

\section{Consideration of surgery}

The $30 \%$ of patients who fail to respond to medical management should be considered for an early surgical opinion. There are no published data on the timing or clinical criteria for surgical referral, but it is the authors' clinical practice to refer patients with ongoing signs of sepsis and incomplete pleural drainage on the fifth day of medical management. Conversely, patients who have residual pleural fluid, but are otherwise well with improving clinical and laboratory parameters, will normally have gradual resolution of the pleural fluid from the pleural space over time. Video-assisted thoracoscopic surgery (VATS) enables decortication of pleural thickening, septation division and fluid removal, allowing lung re-expansion. VATS is performed under general anaesthesia with single lung ventilation, but in expert centres this can be performed using regional anaesthesia. Several studies have investigated the role of primary VATS versus chest tube drainage on initial presentation with pleural infection, but the methodological limitations of these studies means that definitive evidence is lacking.

\section{Nutritional support}

Weight loss and low serum albumin concentration are commonplace in pleural infection and associated with poorer outcome. ${ }^{22}$ Specific nutritional therapy has not been subject to an RCT in this setting, but nutritional support is likely to be important in counteracting the catabolic state associated with infection. The patient should receive regular dietetic review with institution of continuous enteral feeding if regular oral supplements are not tolerated or ineffective to maintain weight.

\section{Long-term outcome}

Approximately $20 \%$ of patients will die and $15 \%$ require surgery to treat their pleural infection adequately. Despite this, provided patients survive to one year, long-term outcomes are favourable. Radiographic pleural abnormalities often take many months to resolve, but are usually not associated with symptomatic impairment. The development of significant pleural fibrosis sufficient to cause activity restriction is very rare.

\section{Conclusions}

Given the significant morbidity associated with pleural infection, early differentiation of simple and complicated effusions is critical to determine which patients require chest tube insertion rather than antibiotic therapy alone. Pleural fluid $\mathrm{pH}$, analysed using a blood gas machine, allows such rapid clinical differentiation. Adjunctive use of combination intrapleural tPA and DNase shows promise, but further large-scale randomised trials are required to demonstrate mortality and surgery reduction benefits in defined populations.

\section{References}

1 Maskell NA, Batt S, Hedley EL et al. The bacteriology of pleural infection by genetic and standard methods and its mortality significance. Am J Respir Crit Care Med 2006;174:817-23.

2 Finley C, Clifton J, Fitzgerald JM, Yee J. Empyema: an increasing concern in Canada. Can Respir J 2008;15:85-9.

3 Farjah F, Symons RG, Krishnadasan B, Wood DE, Flum DR. Management of pleural space infections: a populationbased analysis. J Thorac Cardiovasc Surg 2007;133:346-51.

4 Maskell NA, Davies CW, Nunn AJ et al. UK controlled trial of intrapleural streptokinase for pleural infection. $N$ Engl J Med 2005;352:865-74.

5 Davies CW, Kearney SE, Gleeson FV, Davies RJ. Predictors of outcome and longterm survival in patients with pleural infection. Am J Respir Crit Care Med 1999;160(5 Pt 1):1682-7.

6 Taryle DA, Potts DE, Sahn SA. The incidence and clinical correlates of parapneumonic effusions in pneumococcal pneumonia. Chest 1978;74:170-3.

7 Chalmers JD, Singanayagam A, Murray MP et al. Risk factors for complicated parapneumonic effusion and empyema on presentation to hospital with communityacquired pneumonia. Thorax 2009;64:592-7.

8 Wrightson JM, Maskell NA. Thoracic ultrasound for beginners: utility and training issues for clinicians. Br J Hosp Med (Lond) 2011;72:325-30.

9 Rahman NM, Singanayagam A, Davies HE et al. Diagnostic accuracy, safety and utilisation of respiratory physician-delivered thoracic ultrasound. Thorax 2010;65: 449-53.

10 Wrightson JM, Fysh E, Maskell NA, Lee YC. Risk reduction in pleural procedures: sonography, simulation and supervision. Curr Opin Pulm Med 2010;16:340-50.

11 Duncan DR, Morgenthaler TI, Ryu JH, Daniels CE. Reducing iatrogenic risk in thoracentesis: establishing best practice via experiential training in a zero-risk environment. Chest 2009;135:1315-20.

12 Davies HE, Davies RJ, Davies CW; BTS Pleural Disease Guideline Group. Management of pleural infection in adults: British Thoracic Society Pleural Disease Guideline 2010. Thorax 2010;65 (Suppl 2):ii41-53.

13 Havelock T, Teoh R, Laws D, Gleeson F; BTS Pleural Disease Guideline Group. Pleural procedures and thoracic ultrasound: British Thoracic Society Pleural Disease Guideline 2010. Thorax 2010;65(Suppl 2):ii61-76.

14 Rapid Response Report, Chest drains: risks associated with the insertion of chest drains. London, UK: NHS National Patient Safety Agency, 2008. www.nrls.npsa.nhs.uk/ resources/type/alerts/?entryid $45=59887$ 
15 Royal College of Radiologists. Ultrasound training recommendations for medical and surgical specialties. London: Faculty of Clinical Radiology, Royal College of Radiologists, 2005. www.rcr.ac.uk/docs/ radiology/pdf/ultrasound.pdf

16 Light RW, Macgregor MI, Luchsinger PC, Ball WC Jr. Pleural effusions: the diagnostic separation of transudates and exudates. Ann Intern Med 1972;77:507-13.

17 Light RW. Pleural diseases, 5th edn. Philadelphia, USA: Lippincott Williams \& Wilkins, 2007.
18 Heffner JE, Brown LK, Barbieri C, DeLeo JM. Pleural fluid chemical analysis in parapneumonic effusions. A meta-analysis. Am J Respir Crit Care Med 1995;151:1700-8.

19 Grijalva CG, Zhu Y, Nuorti JP, Griffin MR. Emergence of parapneumonic empyema in the USA. Thorax 2011;66:663-8.

20 Rahman NM, Maskell NA, Davies CW et al. The relationship between chest tube size and clinical outcome in pleural infection. Chest 2010;137:536-43.

21 Rahman NM, Maskell NA, West A et al. Intrapleural use of tissue plasminogen acti- vator and DNase in pleural infection. $N$ Engl J Med 2011;365:518-26.

22 Ferguson AD, Prescott RJ, Selkon JB, Watson D, Swinburn CR. The clinical course and management of thoracic empyema. QJM 1996;89:285-9.

Address for correspondence: Dr JM Wrightson, Oxford Pleural Unit, Oxford Centre for Respiratory Medicine, Churchill Hospital, Oxford OX3 7LJ. Email: johnwrightson@thorax.org.uk

\section{Respiratory medicine (71567)}

\section{Self-assessment questionnaire}

Trevor Rogers

SAQs and answers are ONLINE for RCP fellows and collegiate members

The SAQs printed in the CME section can only be answered online to achieve external CPD credits.

Any comments should be sent in via email only: clinicalmedicine@rcplondon.ac.uk

\section{Format}

SAQs follow a best of five format in line with the MRCP(UK) Part 1 exam. Candidates are asked to choose the best answer from five possible answers.

\section{The answering process}

1 Go to www.rcplondon.ac.uk/SAQ

2 Log on using your usual RCP username and password

3 Select the relevant CME question paper

4 Answer all 10 questions by selecting the best answer from the options provided

5 Once you have answered all the questions, click on Submit

\section{Registering your external CPD credits}

Carrying out this activity allows you to claim two external CPD credits. These will be automatically transferred to your CPD diary, where you can review the activity and claim your points.
We thank John S Scadding for his help in devising an appropriate MRCP/SCE format.

1 A 66-year-old man with severe chronic obstructive pulmonary disease (COPD) presented with weight loss, from 65 to $55 \mathrm{~kg}$, over a period of three years. He was breathless on exertion, managing to walk about $50 \mathrm{~m}$ before having to stop. He had a chronic cough, productive of mucoid sputum most mornings. He reported that he did not sleep well, but enjoyed helping to care for his grandchildren. He had given up smoking fours years previously. On examination he was cachectic. He was well-oxygenated $\left(\mathrm{SaO}_{2} 94 \%\right)$ breathing room air, but breathless on undressing.

Investigations:

chest X-ray hyperinflated lungs

thyroid function normal

What is the most likely explanation for the weight loss?
(a) COPD
(b) depression
(c) lung cancer
(d) malabsorption
(e) opportunist mycobacterial infection

2 A 40-year-old woman, with a body mass index (BMI) of $41 \mathrm{~kg} / \mathrm{m}^{2}$, attended clinic complaining of daytime somnolence, peripheral oedema and early morning headaches.

Investigations:

Overnight home pulse oximetry

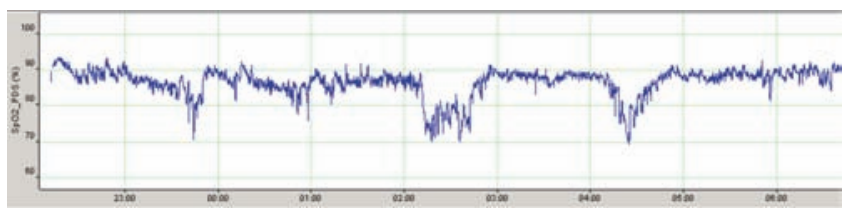

What is the most likely diagnosis?

(a) chronic obstructive pulmonary disease (COPD)

(b) combined obstructive sleep apnoea and obesity hypoventilation syndrome 